\title{
Computer Modeling and Wind Simulation of Lekki Cable Stayed Bridge in predicting an Aeroelastic Effects
}

\author{
[ Hassan Abba Musa, Inuwa Ibrahim Aminu, Shuaibu Umar]
}

\begin{abstract}
The paradigm shifts in the history of predicting the wind related effects was shifted from early theoretical, numerical, experimental techniques, to Computer techniques in fully understanding the vibrational characteristics of a system like Bridge. Therefore, the structural dynamic analysis includes determination of the natural mode shapes and frequencies of an elastic structure in free unforced vibration. In this research paper, the software like ANSYS and others whose built based on Finite Element Method are adapted and well suited for this type of analysis since the mode shapes can be accurately derived from the geometrically complex of the structures, such as beams, and pylons sections that commonly found in slender structure like bridge. The FE structural model is typically formulated in SOLID-Works software as an Eigensystem, where the eigenvalues and eigenvectors represent the natural frequencies and the mode shapes, respectively. The lowest eigenvalues $(1.1006 \mathrm{e}-008 \mathrm{~Hz})$ correspond to the lowest characteristic frequencies of the physical system of Lekki Bridge and are typically more interesting than the higher modes simply because the physical system tends to experience the lower modes as dominant vibration frequencies.
\end{abstract}

Keywords-Computer Techniques, Vibrational characteristics, Lekki Bridge, ANSYS, SOLID- Works, Eigen System.

\section{Introduction}

Cable-stayed and suspension bridges are amongst the largest man-made structures on earth and because of their grandeur; they have always captured the attention and imagination of the public. Its designed as platforms for carrying people across treacherous waters and deep gorges, this must convey the same sense of stability and security as stiff and heavy brick or concrete arches. However, the relative lightness, flexibility and low damping of cable-stayed and suspension bridges means that; they are at risk of being excited into sizeable motion by environmental forces to the astonishment and discomfort of the public. Although cable-stayed and suspension bridges both are held up by cables, their modes of operation are very different. Early suspension bridges in Europe and North America had a strange tendency to be damaged or destroyed by storm winds. From the year 1818 to 1889 a total of 10 suspension bridges were seriously damaged some of them several times.

On 29 November 1836 the third span of the Brighton Chain Pier was wrecked in a storm described as being as a

Hassan Abba Musa, Inuwa Ibrahim Aminu, Shuaibu Umar. Nigerian Building and Road Research Institute (NBRRI), Abuja - Nigeria,

\section{$+2347038183898$}

tropical hurricane by Lieutenant Colonel Reid of the Royal Corps of Engineers. In a written record of the incident Reid describes how oscillations of the bridge deck preceded the fatal undulating motion\| shown in an accompanying sketch, Fig. 1.1 to the trained eye; the sketch displays the first asymmetrical vertical Eigen-mode of a typical suspension bridge indicating that the collapse was linked to resonant excitation [1]

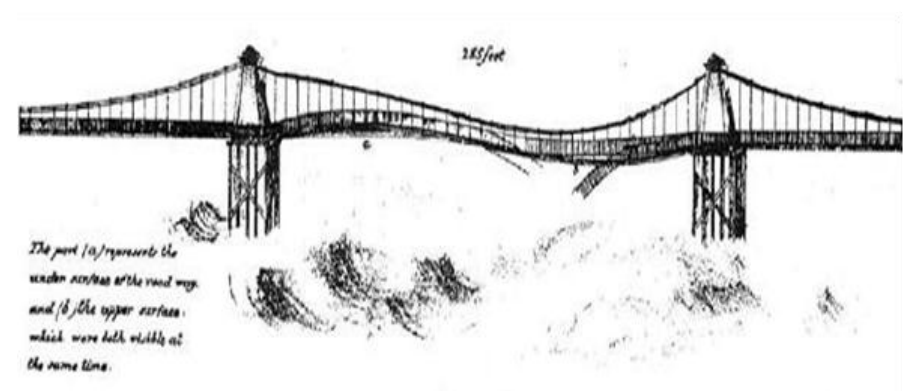

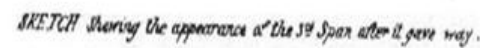

Figure 1.1. Fatal undulating motion of the third span of the Brighton Chain Pier in the storm of 1836 sketched by Ried (J.S. Russell, 1839)

\section{Significant of the Research}

The tendencies in the design of bridges are going in the direction of architecturally daring, more and more lightweight structures, and this also increase the vulnerability to aero- elastic instabilities responses of bridge structures since, amongst other parameters, the bridge Eigen-frequencies are decreased to extremely low values, sometimes well below $1 \mathrm{~Hz}$. The Millennium Bridge in London, which had to be closed down to the public due to excessive oscillations under pedestrian excitation, this was the most glaring example, but similar problems are encountered more and more often. A similar vulnerability can also exist for wind excitation with velocity as low as 42 mph; and the combination of the Eigen-frequencies and the aerodynamic properties describe the structural response of the bridge. Since this problem is prohibitively difficult to solve analytically, this would entail the solution of the coupled wind - structure problem for extremely irregular bluff bodies with complex geometries, in this regard numerical solutions are still impossible and will remain so in the foreseeable future.

Today, extremely sophisticated Finite Element procedures are available, cheap and routinely used for the calculation of deformations and stresses, both in the static and the dynamic realm. A combination of these FE-techniques with measured 
Proc. of The Seventh Intl. Conf. on Advances in Civil, Structural and Environmental Engineering - ACSEE 2018

Copyright (C) Institute of Research Engineers and Doctors, USA. All rights reserved.

ISBN: 978-1-63248-158-0 doi: 10.15224/978-1-63248-158-0-12

aerodynamic/aero-elastic properties would yield a numerical procedure which cannot and should not substitute wind tunnel testing, but it could augment these tests and allow parameter studies in the computer which is fast and relatively inexpensive.

The history of dynamically wind-sensitive suspension bridges and cable-stayed bridges from the nineteenth century onwards, including the periodic failures that have occurred, has been well documented [2,3]. Most of the early interest problem was in the drag, or along wind forces, and Baker [4], Kernot [5] and others, noted that the peak wind forces acting on large areas, such as a complete bridge girder, were considerably less than those on a small plate or board. However, the great American Engineer of suspension bridges John Roebling was aware of the dynamic effects of wind as early as 1855 .

In the period of 1900s-1940s, the industrial revolution led to attempts to construct more and more challenging structures such as; the first high rise structures, and ever longer suspension bridges. This era saw the birth of three of the main wind engineering tools. Firstly, there was the development of the wind tunnel. Eiffel made his first wind tunnel measurements in $1909 \mathrm{~s}$ and in the 1930s, Irminger made measurements on building models in low turbulence wind tunnels. Secondly, there was the development of codes of practice with the realization of the need to provide Engineers with practical guidance on design to enable environmental loads such as wind to be properly defined. The first UK code of practice was published in 1944 (British Standards Institution, 1944). Thirdly, this period saw the beginnings of full-scale measurements of wind loads on structures. It is in the interaction between wind tunnel and full- scale tests that most progress was made in the field of wind engineering during this period. On November 7, 1940, is the first Tacoma Narrows suspension bridge collapsed due to wind induced vibrations in a $40 \mathrm{mph}$ wind just 1 year after its completion. This led to changes in bridge construction ever after [6].

Therefore, these recent years have also been extremely busy in terms of developing codes and revising the wind related problems across the world. In nutshell, the period has seen an increasing application of modern analytical methods and computer applications to wind engineering particularly advanced probabilistic techniques, wavelet analysis, orthogonal decomposition, Finite Element Method, etc. [7], of much significance that the ability of recognizing the natural Eigen system (Frequency and mode shape) in predicting the vibrational characteristic behavior of the system (Bridge) from its geometric properties.

\section{Methodology}

\section{A. Lekki-Ikoyi Cable Bridge Parametric Data}

The Lekki-Ikoyi link cable stayed bridge touts not just Nigeria's but sub-Saharan African first longest cable stayed bridge as shown in Figure 3.1. The bridge constructions started from 2008 and completed in the year 2013; but officially opened to the traffic on 29 of May, 2013.

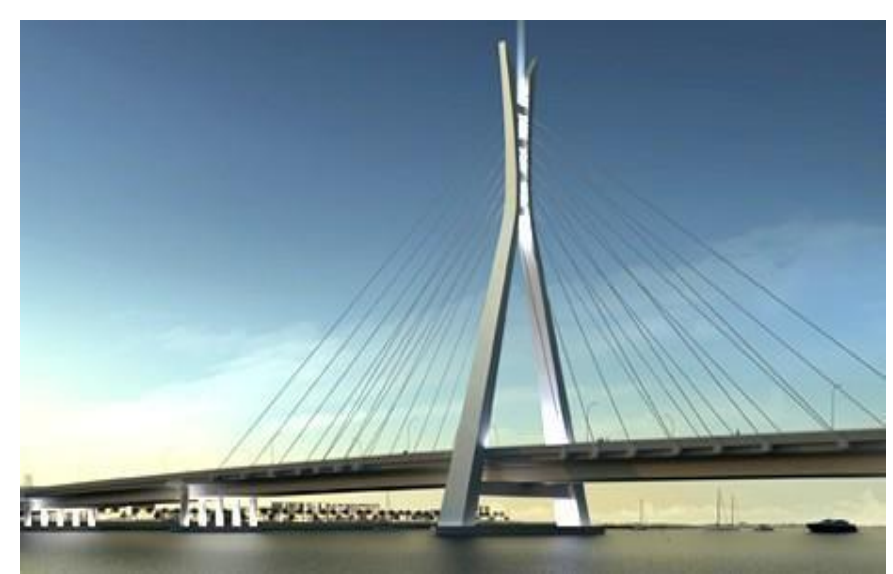

Figure 3.1. Lekki cable stayed bridge (Julious Berger Plc, 2013)

The bridge technical details are briefly described as follows - Total span of $1.358 \mathrm{~km}$ comprising of two principal parts: a 722-metre long full 'Span Approach Bridge' and a 635metre long cable-stayed bridge with a precast structure called the 'Main Bridge'; length of cable - 170m. Two (2) Pylons- $87 \mathrm{~m}$ from water level (with A-shaped up to $50 \mathrm{~m}$ ); Navigational requirement clearance average of $9 \mathrm{~m}$ above high water level. Width lane - $16 \mathrm{~m}$ across ( $8 \mathrm{~m}$ on both sides), Walkways - $4 \mathrm{~m}$ across ( $2 \mathrm{~m}$ on both sides), road works - $338.7 \mathrm{~m}$ while Lekki end is about $311.5 \mathrm{~m}$. The bridge design required specialized engineering know-how and the construction made necessary the need to introduce and understand the new methods. The main bridge section comprises pre-cast segmental box girder elements installed according to the balanced cantilever principle utilizing tailor-made launching girder and lifting frames. Figure 3.2 below shows the main deck cross section and cantilevered construction techniques.

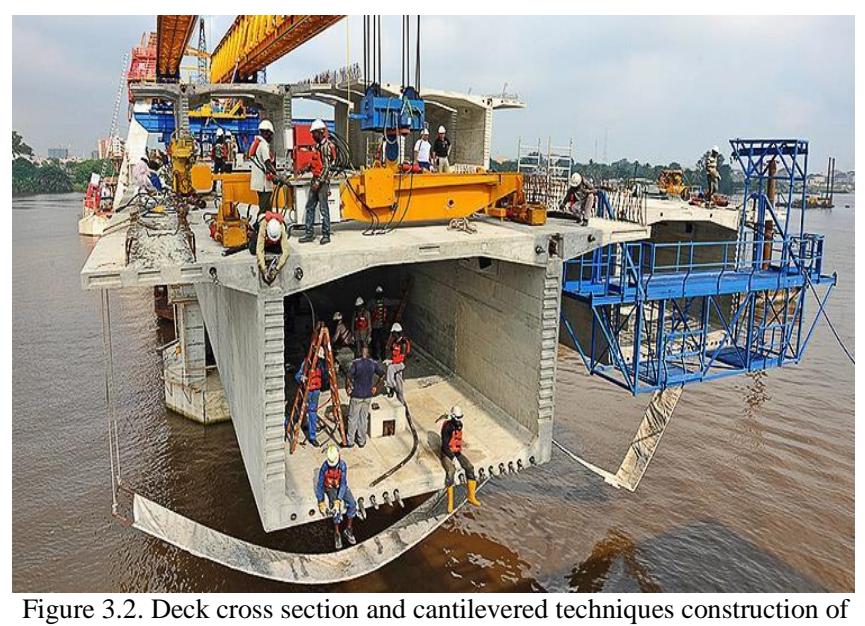
Lekki Bridge (Julious Berger Plc, 2013)

\section{B. Modeling of the Lekki Cable Stayed Bridge}

The structural modeling was partly made using SOLIDWORKS Software, and imported as external file to ANSYS workbench as shown in figure 3.3 , in which a full three dimensional finite model was finally conceived in the software because of its significant capability to account for the initial cable tension, and pre-stressed modal analysis capability. 
Proc. of The Seventh Intl. Conf. on Advances in Civil, Structural and Environmental Engineering - ACSEE 2018

Copyright (C) Institute of Research Engineers and Doctors, USA. All rights reserved.

ISBN: 978-1-63248-158-0 doi: 10.15224/978-1-63248-158-0-12

\section{The Modelling of each part of Bridge}

- Two towers consist of both equivalent and variable sections are discretized by both BEAM4 and BEAM44 elements.

- Four concrete girder decks and one central stringer are modeled as the 3-D elastic beam elements (BEAM4), since they are the structural members possibly subjected to tension, compression, bending and torsion.

- The floor beams are of the same sections and thus they are modeled by the BEAM44 elements.

- All piers, supports and platforms are modeled by the solid elements (SOLID45).

- $\quad$ Stay cables are also modelled with (LINK10) as cable element.

- MASS21 elements are used to include the mass of equilibrium blocks, parapet and anchors that are non-structural members.

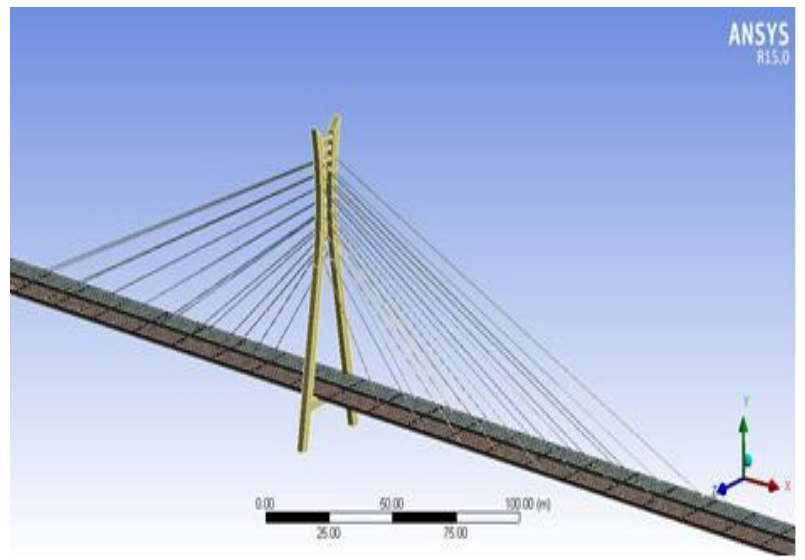

Figure 3.3. Modal View of the 1st Tower of Lekki Bridge

Therefore, Modelling of the stay cables is possible in ANSYS by employing the 3-D tension-only truss elements (LINK10), and utilizing its stress-stiffening capability. With this element, the stiffness is removed if the element goes into compression, thus simulating a slack cable. The cable sagging effect can be considered with the stress-stiffening capability.

The element is nonlinear and requires an iterative solution, and each stay cable is modeled by one element. Details on numbers of elements and nodes of the above Bridge Parts are all reported in the subsequent sections and tables along with their material properties.

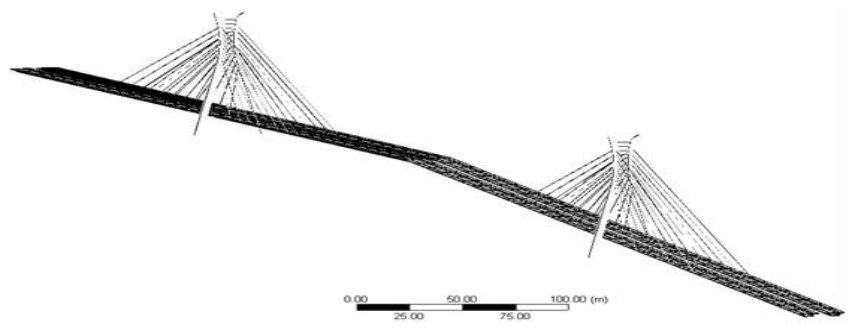

Figure 3.4. Side View of discretized Lekki Bridge

\section{Bridge Boundary Condition}

The modelling of bridge boundary conditions is an important issue in the dynamic analysis. Two types of bridge bearings - fixed and expansion bearing were used in End Support 1 and 2 of the Lekki cable-stayed bridge respectively. In this model, bridge bearings are modeled by a set of rigid link elements connecting the superstructure and supports. To simulate the actual behavior, the fixed and expansion bearings are simulated by coupling the corresponding translational and rotational degrees of freedom at both end nodes of the link elements.

\section{E. Material Properties Data}

The materials are defined as concrete, steel and cable in which are assigned to appropriate members of the bridge. The materials and its geometric properties are all considered.

\section{F. Material Properties Data}

The model geometry of the bridge was well connected based on the specific boundary condition defined in Section D above and set to be mesh for qualitative results. The Model mesh details are shown in table 3.1 below-

Table 3.1. Model mesh

\begin{tabular}{|c|c|}
\hline Object Name & Mesh \\
\hline State & Solved \\
\hline \multicolumn{2}{|c|}{ Sizing } \\
\hline Relevance Center & Fine \\
\hline Element Size & Default \\
\hline Initial Size Seed & Active Assembly \\
\hline Smoothing & Medium \\
\hline Transition & Fast \\
\hline Span Angle Center & Coarse \\
\hline Minimum Edge Length & $109.290 \mathrm{~mm}$ \\
\hline \multicolumn{2}{|c|}{ Inflation } \\
\hline Inflation Option & Smooth Transition \\
\hline Transition Ratio & 0.272 \\
\hline Maximum Layers & 5 \\
\hline Growth Rate & 1.2 \\
\hline \multicolumn{2}{|c|}{ Statistics } \\
\hline Nodes & 75595 \\
\hline Elements & 15964 \\
\hline Mesh Metric & None \\
\hline
\end{tabular}


Proc. of The Seventh Intl. Conf. on Advances in Civil, Structural and Environmental Engineering - ACSEE 2018 Copyright (C) Institute of Research Engineers and Doctors, USA. All rights reserved.

ISBN: 978-1-63248-158-0 doi: 10.15224/978-1-63248-158-0-12

\section{Result}

\section{A. Eigen-Frequency of the Bridge}

The model based on its parameters represents the Eigenfrequencies and modes of vibration of the entire bridge scale to give insight on the flutter speed and frequency that will make it unstable. The table 4 represents first 12 natural frequencies and its maximum displacements ranges from lateral, vertical and rotational bending.

Table 4.1. Table Type Styles

Figure 4.1. $1^{\text {st }}$ Lateral bending

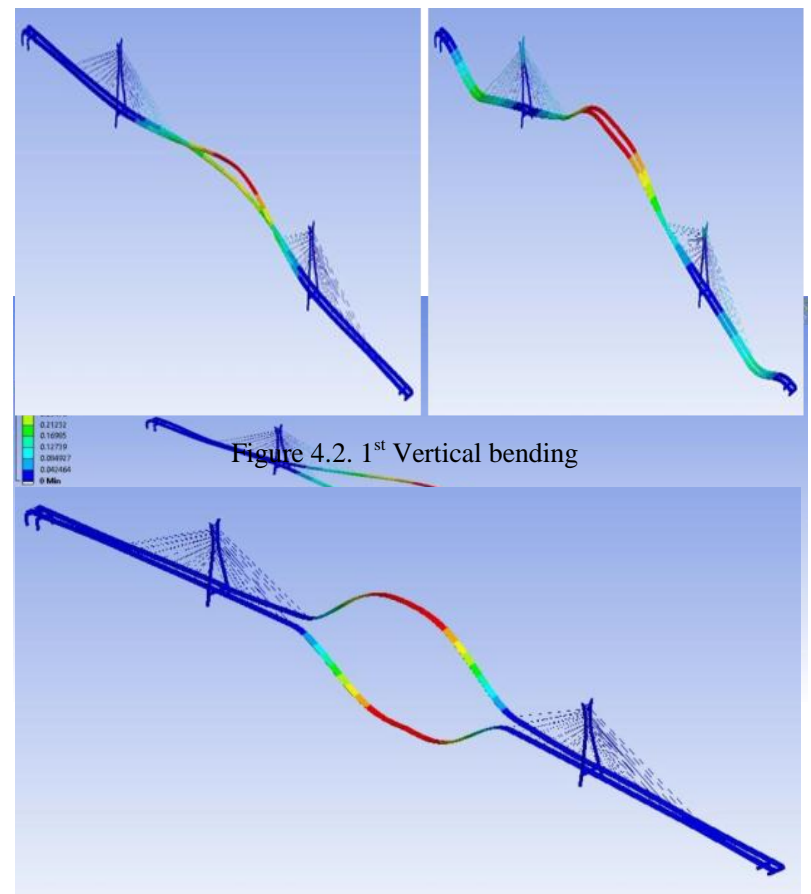

Figure 4.3. $2^{\text {nd }}$ Vertical bending

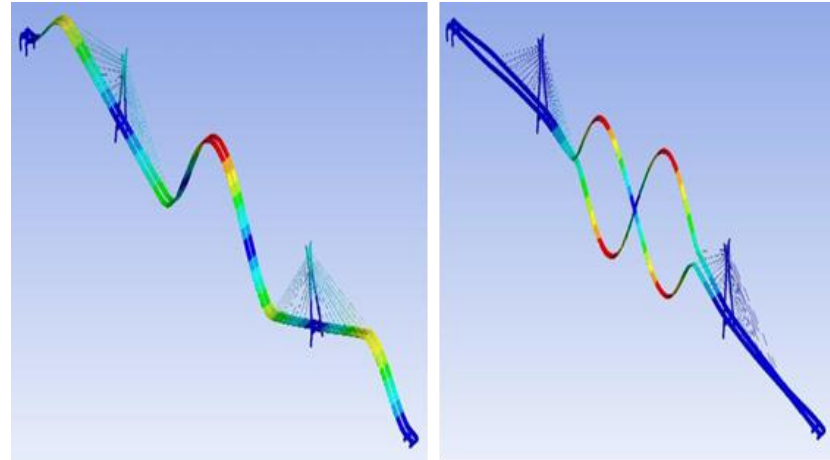

Figure 4.4. $3^{\text {rd }}$ Vertical bending

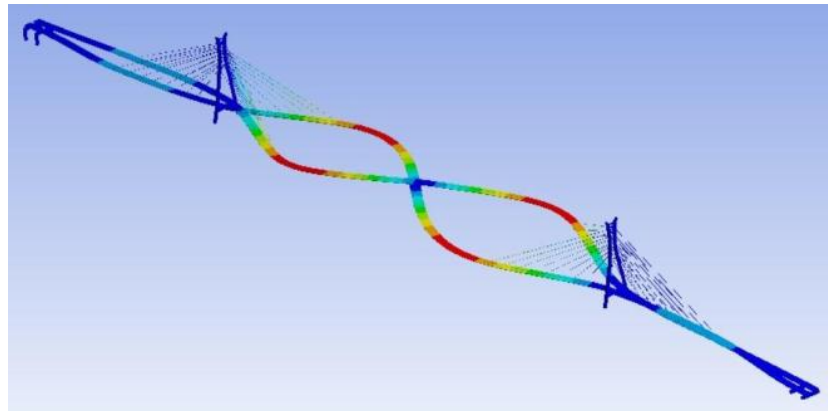

Figure 4.5. $2^{\text {nd }}$ Lateral bending

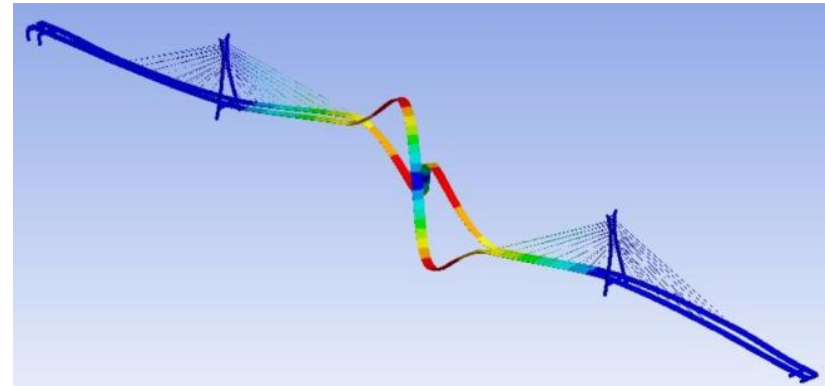

Figure 4.6. $1^{\text {st }}$ Rotational bending

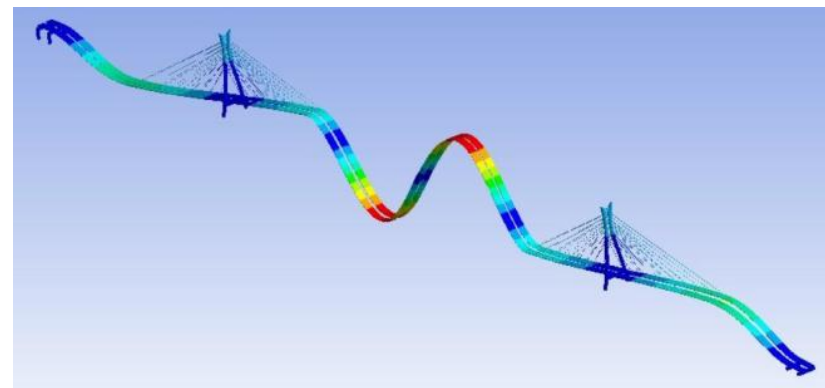

Figure 4.7. $4^{\text {th }}$ Vertical bending

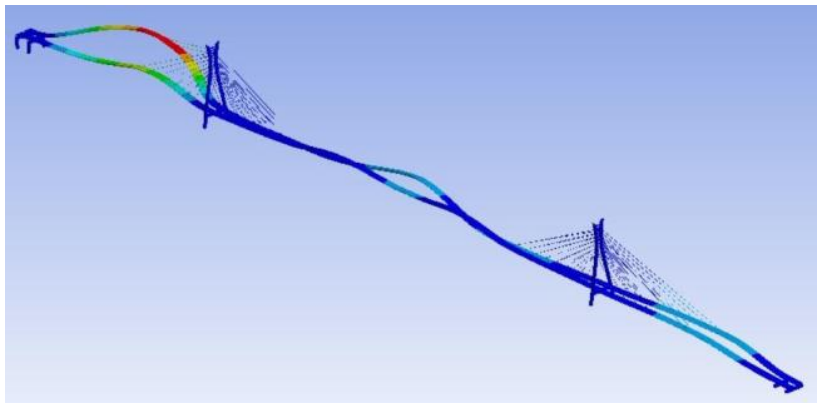


Proc. of The Seventh Intl. Conf. on Advances in Civil, Structural and Environmental Engineering - ACSEE 2018

Copyright (C) Institute of Research Engineers and Doctors, USA. All rights reserved.

ISBN: 978-1-63248-158-0 doi: 10.15224/978-1-63248-158-0-12

\begin{tabular}{|l|l|l|}
\hline Mode & Frequency [Hz] & Amplitude [mm] \\
\hline 1. & $1.1006 \mathrm{e}-008$ & 0.01254 \\
\hline 2. & $1.2097 \mathrm{e}-008$ & 0.38638 \\
\hline 3. & $1.3262 \mathrm{e}-008$ & 0.42053 \\
\hline 4. & $2.5845 \mathrm{e}-008$ & 0.25214 \\
\hline 5. & $7.7419 \mathrm{e}-005$ & 0.39298 \\
\hline 6. & $7.8404 \mathrm{e}-005$ & 0.38217 \\
\hline 7. & $9.6906 \mathrm{e}-005$ & 0.38638 \\
\hline 8. & $1.0210 \mathrm{e}-004$ & 0.30933 \\
\hline 9. & $1.2157 \mathrm{e}-004$ & 0.26134 \\
\hline 10. & $1.3949 \mathrm{e}-004$ & 0.39298 \\
\hline 11. & $1.8345 \mathrm{e}-004$ & 0.30437 \\
\hline 12. & $1.8829 \mathrm{e}-004$ & 0.38187 \\
\hline 13. & $1.9262 \mathrm{e}-004$ & 0.31127 \\
\hline 14. & $2.1821 \mathrm{e}-004$ & 0.31679 \\
\hline 15. & $3.1682 \mathrm{e}-004$ & 0.36586 \\
\hline 16. & $3.2215 \mathrm{e}-004$ & 0.52561 \\
\hline
\end{tabular}

considered as a critical wind speed (flutter speed) which can make the bridge to be dynamically unstable.

The first mode at $1.1006 \mathrm{e}-008 \mathrm{~Hz}$ is dominated by the lateral bending motion as shown by the relative scaling of the maximum characteristic displacement at the deck (right side), and the second modes are dominated by vertical bending for the same reason. Thus, the two lower modes of this model are the primary suspects for consideration of aero-elastic influence since a combination of bending and torsion in phase results in dynamic flutter.

\section{Acknowledgment}

The Authors would like to express their thanks to Prof. A. Mohammed, Dr. Prashant Mukherjee, and Shashi Kant for their invaluable suggestions and inputs toward this research.

\section{References}

[1] Marco L., Vincenzo G., "A Parametric multi body section model for model interactions of cable supported bridges", Journal of Sound and Vibration 333 (2014) 4579-4596.

[2] M. Liu, D. Zuo, N. Jones, "Analytical and numerical study of deckstay interaction in a cable - stayed bridge in the context of field observations", Journal of Engineering Mechanics 139 (11) (2013) 1636-1652.

[3] Belington, DP, 1977, "History and aesthetics in suspension bridges", ASCE Journal of the Structural Division 103: 1655-72.

[4] Baker, B. 1884, "The Forth Bridge", Engineering 38:213.

Figure 4.8. $5^{\text {th }}$ Vertical bending

[5] K. Billah and R. Scanlan, "Resonance, Tacoma Narrows Bridge Failure, and Undergraduate Physics Textbooks", American Journal of Physics, 59(2), 118-124, 1991.

[6] Kernot, W.C, 1983, "Wind Pressure", Proceeding Australian Society for the Advancement of Science V: 573-81.

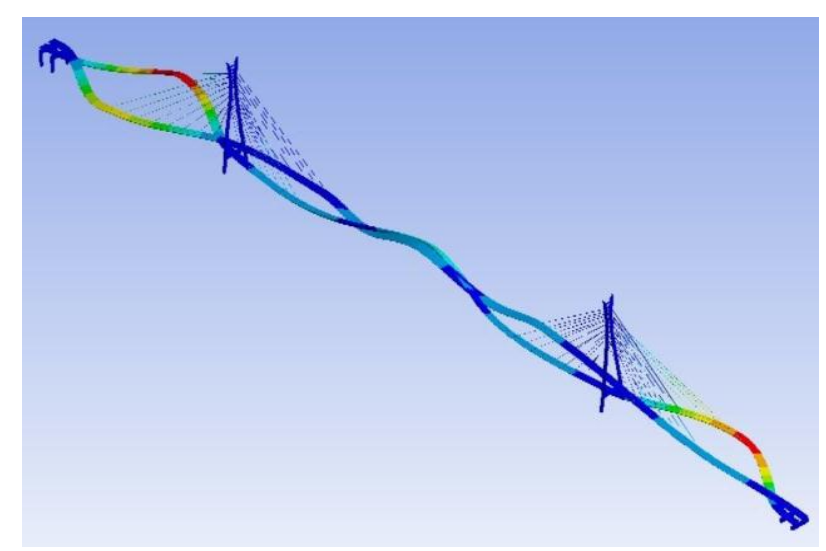

Figure 4.9. $2^{\text {nd }}$ Rotational bending

Kareem, A., 2003, "A tribute to Jack E Cermak-wind effects on structures: a reflection on the Past and Outlook for the future", In: Proceedings of the 11th International Conference on Wind Engineering, Lubbock, pp. 1-28.interface, IEEE Transl. J. Magn. Japan, vol. 2, pp. 740-741, August 1987 [Digests 9th Annual Conf. Magnetics Japan, p. 301, 1982].

\section{B. Discussion}

The modal analysis was performed by the general structural analysis software ANSYS and the result show that the natural frequencies of the bridge are very closely spaced together with range from $1.1006 \mathrm{e}-8$ to $3.2215 \mathrm{e}-4$; including 5 vertical modes, 2 lateral modes, and 2 rotational modes.

\section{v. Conclusion}

The Eigen-frequency of the bridge as obtained from the assumed low wind excitation of $40 \mathrm{mph}$ in the analysis made in ANSYS software resulted to frequencies that are quite below $1 \mathrm{~Hz}$. Therefore, the assumed wind speed can be 